\title{
Fracture mechanisms of polycrystalline advanced ceramics
}

\author{
Marin Petrovic ${ }^{1}$, Elmedin Mesic ${ }^{2}$ \\ ${ }^{1}$ Department of Mechanics, Mechanical Engineering Faculty, University of Sarajevo \\ ${ }^{2}$ Department of Mechanical Structures, Mechanical Engineering Faculty, University of Sarajevo
}

\begin{abstract}
Polycrystalline advanced ceramics are synthetic products produced by sintering together selected ceramics grains in a metal matrix serving as a binder. In order to be able to propose their optimization, achieving high performance cutting and leading to reduced operating costs and improved working environment, relevant fracture mechanisms involved in their failure need to be determined. In this work, experimental results of plane strain fracture toughness obtained earlier on single-edge- $V$-notched-beam specimens were supported with microscopy analysis. These findings establish a clear connection between the fracture toughness results and the fracture mechanisms visible on and beneath the fracture surfaces, revealing adiabatic conditions that occur at the crack tip during fracture.
\end{abstract}

\begin{tabular}{ll}
\hline Keywords: & $\begin{array}{l}\text { Brittle fracture; Fracture mechanics; Impact fracture; Scanning electron microscopy; } \\
\text { Toughness testing }\end{array}$ \\
\hline
\end{tabular}

\section{Corresponding Author:}

Marin Petrovic, Mechanical Engineering Faculty, University of Sarajevo, Vilsonovo setaliste 9, 71000 Sarajevo, Bosnia and Herzegovina.

E-mail: petrovic@mef.unsa.ba

\section{Introduction}

Polycrystalline advanced ceramics are synthetic products manufactured by sintering selected ceramic grains together in a metal matrix. Random orientation of the grains enables high hardness and abrasion resistance in all directions. Cutting tools made of polycrystalline advanced ceramics achieve extraordinary results when machining an extensive range of non-ferrous metals as well as non-metallic materials. The precise, correct and coherent assessment of the fracture toughness and the corresponding fracture mechanisms of these materials are of essential significance to advanced ceramics material producers as well as their end users. The potential to foresee the performance and responses of such materials can guide to better compositions, improved performance, lower costs and augmented safety.

Relative qualities and advantages of five independent methods of fracture toughness investigation were tested by Morrell [1] and Guo et al [2]. These methods included a chevron-notched beam, an indentation fracture, an indentation strength in four-point bending, a single-edge precracked beam in four-point bending (SEPB-B) using popped in bridging cracks, as well as a single edge notch beam - saw cut (SENB-S). A chevron notch is commonly used to obtain controlled crack growth where inceptive cracks strike a region of declining stress intensity. However, as controlled crack growth is often unfeasible in hard material, this feature cannot be exploited in this case. Also, as the introduction of a chevron notch is more complicated than a simple V notch and requires more time, the method was initially outruled for this research. On the other hand, SENB method required very little specialized testing apparatus and specialist skills, which makes it relatively cheap and applicable in most standard fracture laboratories. Also according to [1], amongst all of these alternatives, the SENB method was found to provide the most reproducible results and therefore was chosen for investigation. The findings presented in this paper lead to a greater understanding of the fracture behavior of polycrystalline advanced ceramics, informing the development of improved future grades of material. 


\section{Materials and methods}

Two grades of polycrystalline advanced ceramics have been used for investigation [3] containing different mean WC grain sizes and amounts of cobalt utilized as a binder in the obtained composite. These material grades will be referred to as grade A and grade B and contain average WC grains of 6 and $30 \mu \mathrm{m}$, respectively. As the grade A material contains more grain boundaries, therefore higher percentage of cobalt binder may be anticipated. Cutting of single edge V notched beam (SEVNB) specimens was performed out of bulk circular shaped disks of $50 \mathrm{~mm}$ diameter and two different thicknesses using a laser. The test specimens had the following average dimensions:

- 'thick' samples: (b) $4.73 \mathrm{~mm} \times(h) 6.22 \mathrm{~mm} \times(l) 28.5 \mathrm{~mm}$

- 'thin' samples: $(b) 2.98 \mathrm{~mm} \times(h) 6.22 \mathrm{~mm} \times(l) 28.5 \mathrm{~mm}$.

The specimens were positioned on a three-point bend (TPB) fixture with a span $(S)$ of $24.8 \mathrm{~mm}$ and two supporting rollers with a radius of $3 \mathrm{~mm}$. The load was applied by a stainless steel striker fitted with a loading roller with the same radius of $3 \mathrm{~mm}$. All rollers were made from Inconel alloy 600 (Ni72/Cr16/Fe8) which retains its stiffness at elevated temperatures. Total number of specimens experimentally tested in the TPB layout amounted to 228 pieces. Tests were performed at several loading rates ranging from $1 \mathrm{~mm} / \mathrm{min}$ and 100 $\mathrm{mm} / \mathrm{min}$ on a universal screw driven testing machine [4], across $0.3 \mathrm{~m} / \mathrm{s}$ and $1 \mathrm{~m} / \mathrm{s}$, up to $5 \mathrm{~m} / \mathrm{s}$ on an instrumented drop-weight impact tester. These dynamic rates are the conditions occurring in real cutting processes [5-7]. Choice of loading rates between quasistatic and the highest dynamic rate was taken as a uniform distribution across five decades of the loading rate in logarithmic scale. Three temperature levels were employed: 25,300 and $600^{\circ} \mathrm{C}$ [8], with the highest temperature appearing in real operating conditions [9, 10]. At least three and no more than 5 repetitions were carried out at each possible combination of five loading rates and three temperature levels. The plane strain fracture toughness is determined by the load at initiation method according to ASTM E1820-01 fracture standard, using SEVNB test method according to CEN 14425-5:2004 standard, and presented in Fig. 1. Unfortunately, it was unfeasible to obtain results across the full range of testing conditions for both types of specimens due to their limited supply. However, the number of available specimens and obtained results were very consistent and quite sufficient to appraise arisen effects of different variables on the fracture toughness and draw important conclusions.
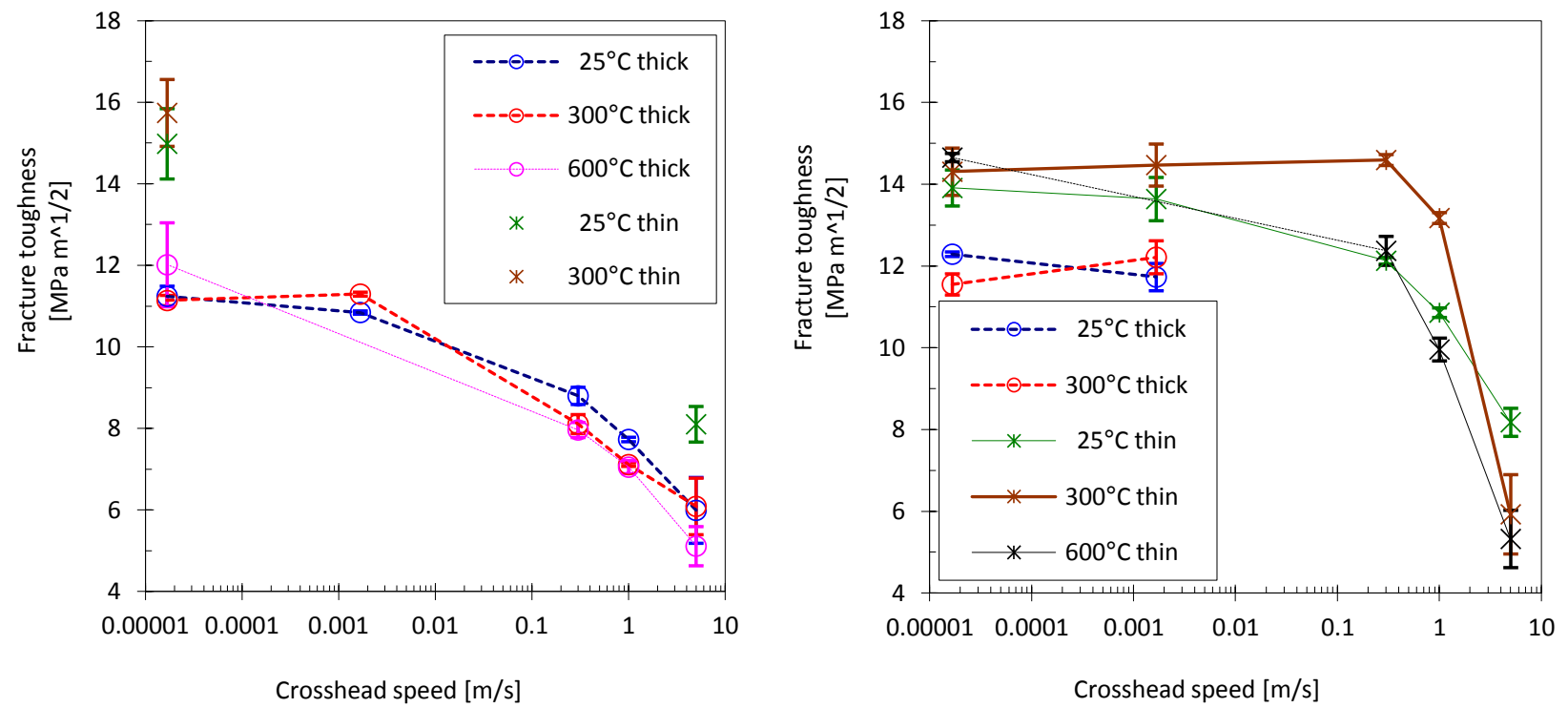

Figure 1. Apparent fracture toughness of grade A (left) and grade B (right) as function of crosshead speed and temperature

Test results in Fig. 1 revealed the apparent fracture toughness $K_{I b}$ of grade A material to remain generally constant at quasi-static rates, and then to decrease with a further increase in the loading rate above 100 $\mathrm{mm} / \mathrm{min}$. It can also be seen from the graph that the material was relatively independent of temperature 
changes up to $300^{\circ} \mathrm{C}$ at lower rates. At $600^{\circ} \mathrm{C}$, it is evident that the grade A material exhibits improved fracture toughness at quasistatic rates where cobalt in the mixture becomes more ductile, while the opposite is true at higher rates (at least at 0.3 and $1 \mathrm{~m} / \mathrm{s}$ ) with a significant difference between room temperature and the elevated temperatures $\left(300^{\circ} \mathrm{C}\right.$ and $\left.600^{\circ} \mathrm{C}\right)$. This can not be claimed with certainty for $5 \mathrm{~m} / \mathrm{s}$ results due to much higher discrepancy and overlap of the standard deviations. Fig. 1 also shows that the apparent fracture toughness of the grade B composite persists relatively constant at quasi-static and intermediate rates up to 0.3 $\mathrm{m} / \mathrm{s}$, and then sharply drops at higher rates. Weak dependence on temperature was observed at quasi-static rates where $K_{I b}$ slightly increases with an increase in temperature, while the temperature effect is considerable at higher rates and sharply decreasing $K_{I b}$ values.

\section{Result discussions}

Optical microscopy is often used as the first step in examining failure or characterizing materials. A Nikon Optiphot SBX1 optical microscope was used in the examination. Characteristic images obtained from grade A rectangular samples fractured at $1 \mathrm{~mm} / \mathrm{min}$ in four-point bending are presented in Fig. 2. Magnification of $5 x$ has been used.

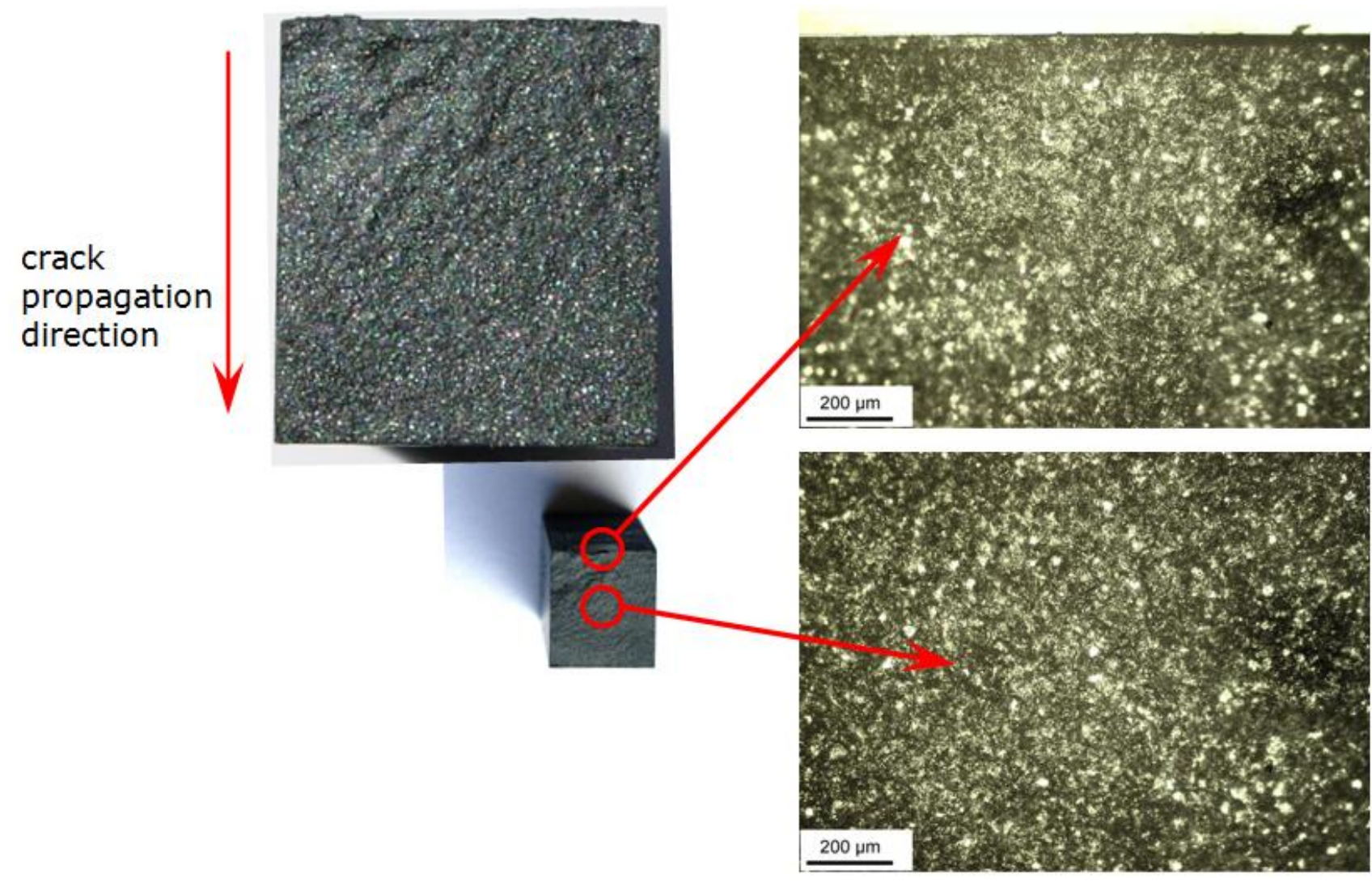

Figure 2. Example of fracture surface images 5x magnified

Clearly, no remarkable information about where the fracture started to propagate can be observed from Fig. 2 at this level of magnification. Therefore it is necessary for the fracture surfaces to be observed under scanning electron microscope (SEM) in order to draw some significant conclusions about the fracture process, allowing surface observation with greater depth of field compared to the optical microscope.

An average resolution Hitachi Tabletop TM-1000 type SEM and a high resolution Dual Beam system field emission gun SEM (FEG-SEM) with energy dispersive X-ray spectroscopy (EDX) were used in the examination. Magnification can be controlled over a wide range from about 20x to 100,000x by the FEGSEM used. More than 1,000 SEM micrographs were taken from 87 fractured specimens and the general trend is given by the following representative images. Fracture surfaces of grade A fractured at $1 \mathrm{~mm} / \mathrm{min}, 0.3 \mathrm{~m} / \mathrm{s}$ and $5 \mathrm{~m} / \mathrm{s}$ are presented in Fig. 3 to Fig. 5, respectively. The examined regions are very close to the notch root for all the specimens, while the direction of fracture propagation is from the bottom to the top of the pictures. 


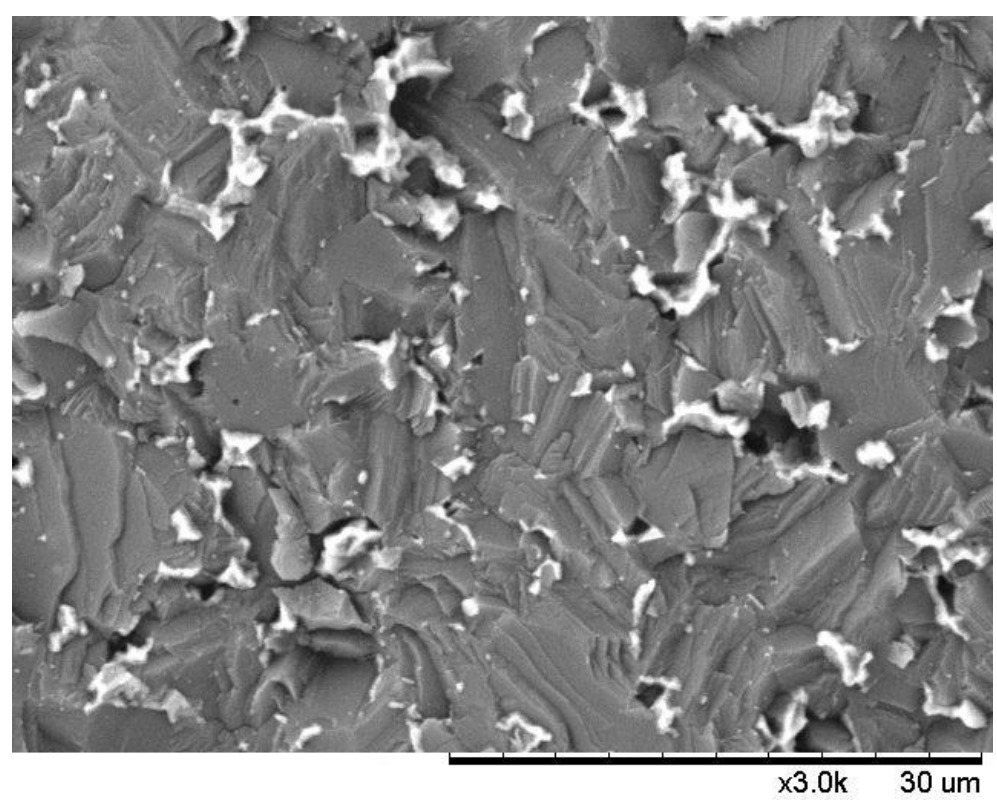

Figure 3. Scanning electron micrograph showing the fracture surface of grade A sample fractured at 1 $\mathrm{mm} / \mathrm{min}$ at a magnification of $3,000 \mathrm{x}$

It can be seen from the Fig. 3 that the mode of fracture at the quasi-static loading rate is almost purely transgranular. The microcrack, once formed, rapidly extends across the grain, but rarely into the other grains, because the lattice directions change at grain boundaries. On the other hand, if the adhesion is strong, a microcrack that meets the grain boundary may initiate a microcrack in the adjacent grain. Because these two microcracks in general have different orientations, they usually touch each other at only one point. In this way a broken sheet of microcracks is created along the prospective forward growth direction of the main crack. The resulting fracture surface is stepwise flat, showing glittering faces, with usually 'fibrous' borders between them. Very often the fracture path does not even change direction at the grain boundary, but follows the direction of maximum stress regardless of crystal orientation. Occasionally, some internal flaws, such as poorly bonded grains, triggered fracture to propagate through the grain boundaries, resulting in the appearance of a certain amount of intergranular fracture.

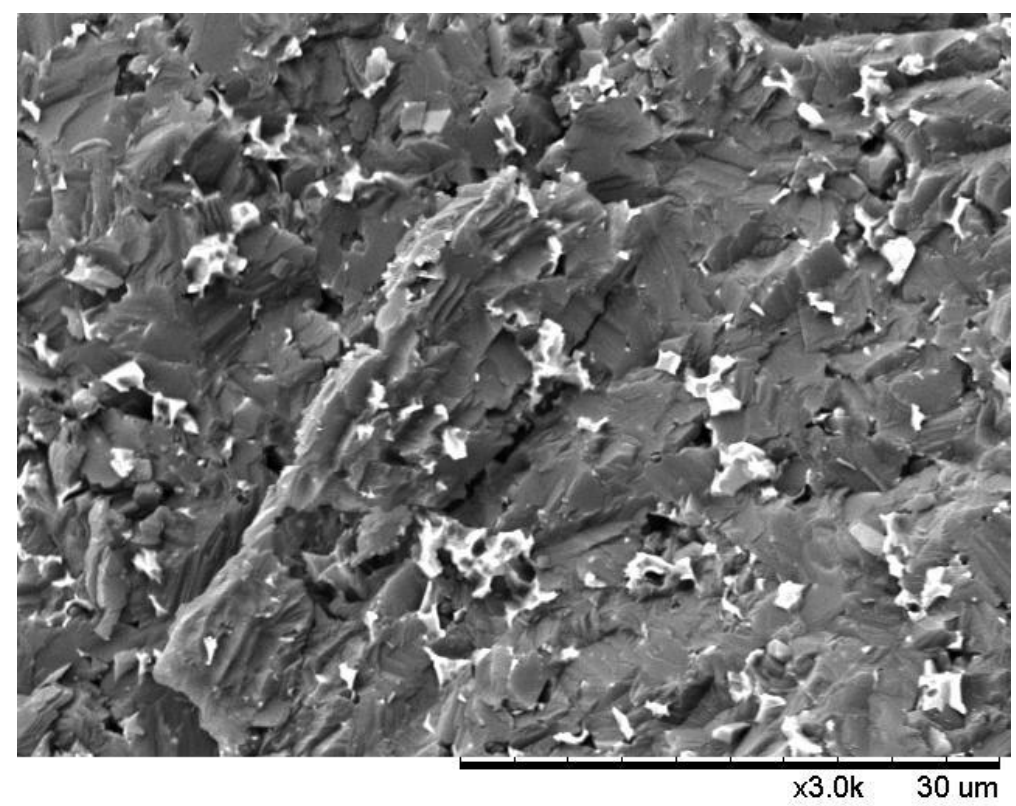

Figure 4. Scanning electron micrograph showing the fracture surface of grade A sample fractured at $0.3 \mathrm{~m} / \mathrm{s}$ at a magnification of $3,000 \mathrm{x}$ 
As the loading rate increases, the proportion of intergranular fracture also increases. Fracture surfaces become rougher with lots of separation regions and subsurface microcrack formations, as can be seen in Fig. 4 . At 5 $\mathrm{m} / \mathrm{s}$, fracture was found to be predominantly intergranular where the crack changes direction to follow the new grain. This results in a fairly jagged looking fracture with bumpy edges, as shown in Fig. 5.

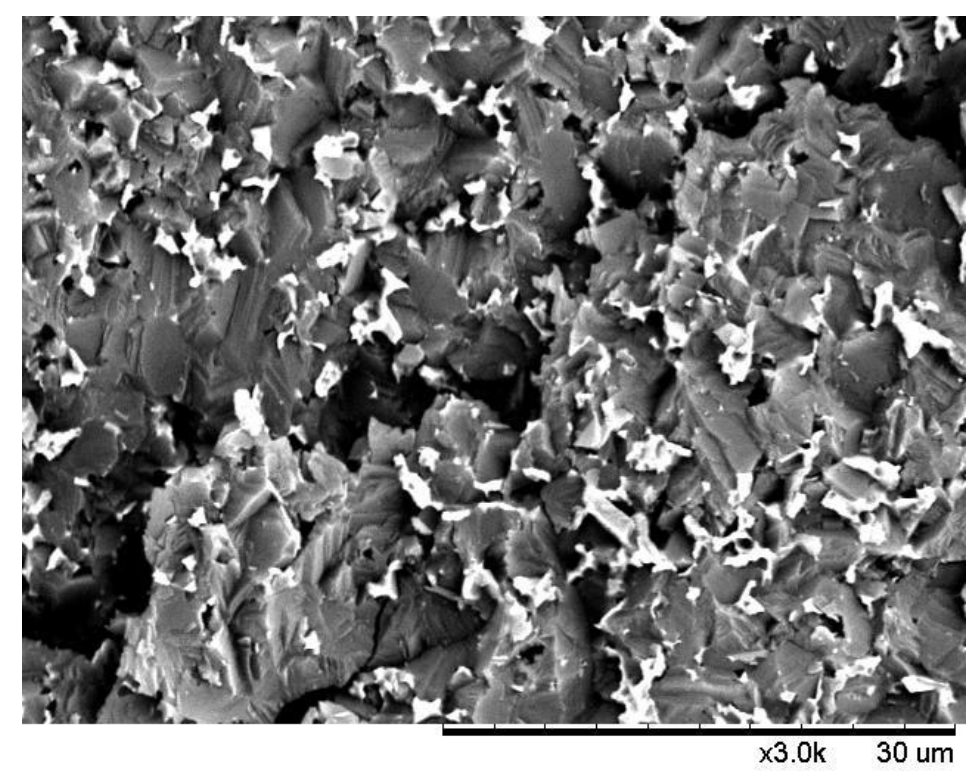

Figure 5. Scanning electron micrograph showing the fracture surface of grade A sample fractured at $5 \mathrm{~m} / \mathrm{s}$ at a magnification of $3,000 \mathrm{x}$

A closer view of the fracture path between the grains in grade A fractured at $5 \mathrm{~m} / \mathrm{s}$ is given in Fig. 6 , showing the fracture surface with $20,000 \mathrm{x}$ magnification. Light elements in this fractograph represent cobalt. Characteristics of intergranular fracture such as jagged looking surface and WC grain offprints in cobalt can be clearly seen, while the small amount of transgranular fracture also took place close to the right manifesting itself through the steppings.

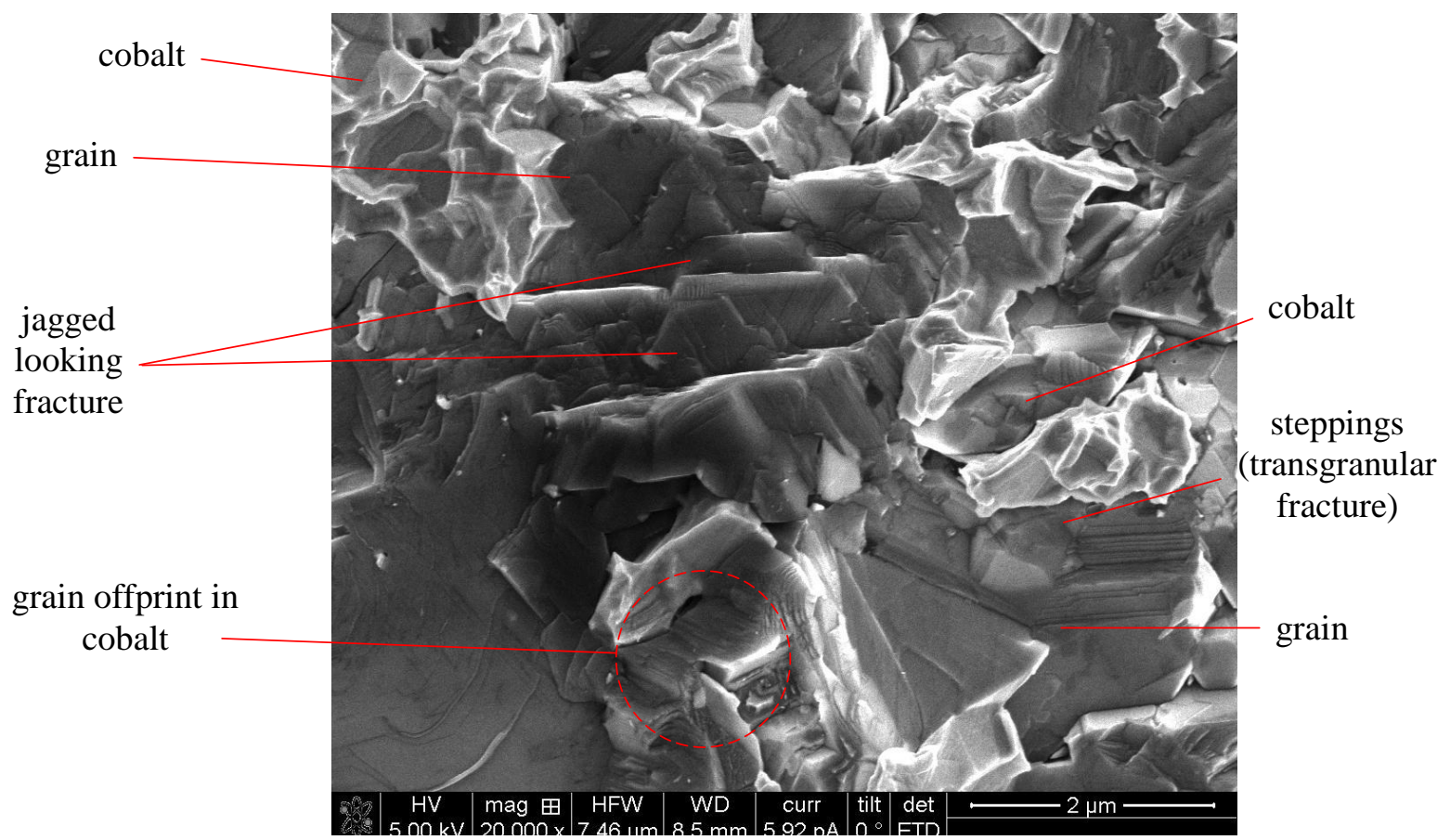

Figure 6. Scanning electron micrograph showing fracture appearance for grade A sample fractured at $5 \mathrm{~m} / \mathrm{s}$ at a magnification of $20,000 \mathrm{x}$ 
Fracture surfaces of grade B samples fractured at $1 \mathrm{~mm} / \mathrm{min}, 0.3 \mathrm{~m} / \mathrm{s}$ and $5 \mathrm{~m} / \mathrm{s}$ are given in Fig. 7 to Fig. 9 , respectively. Again, scanned regions are very close to the root of the notch for all specimens, while the direction of fracture propagation is upwards.

A greater mixture of intergranular and transgranular fractures than that of grade A specimens across all the loading rates is visible from the presented images. However, the crack propagation at quasistatic loading rates, and even at intermediate rates, is predominantly transgranular, while it is becoming increasingly intergranular at high rates.

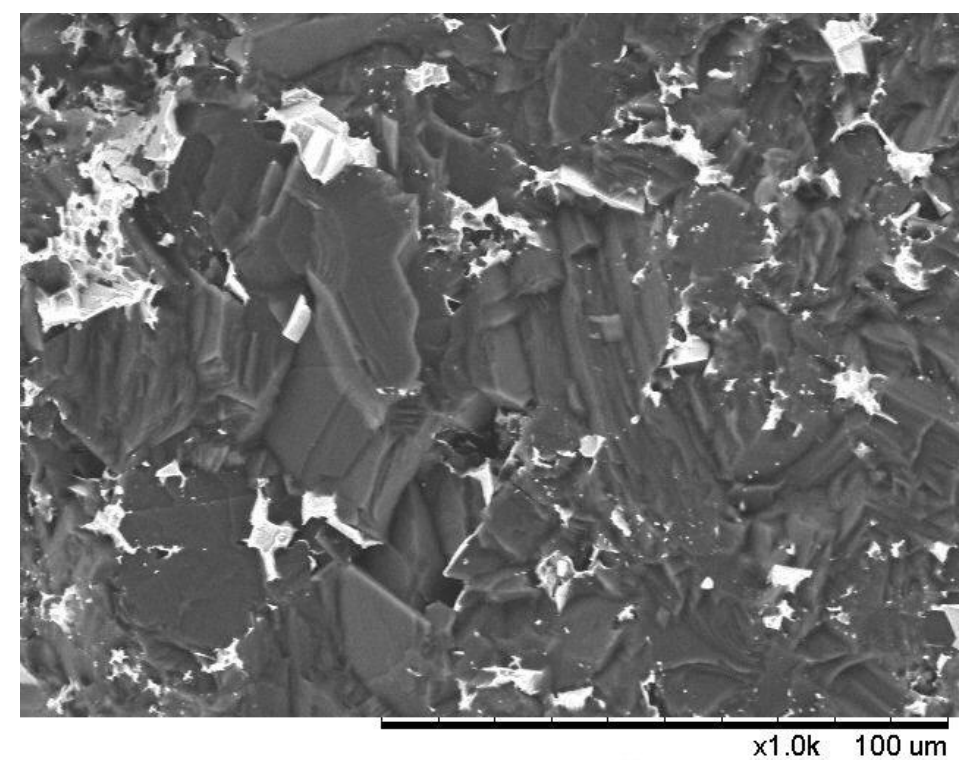

Figure 7. Scanning electron micrograph showing the fracture surface of grade B sample fractured at $1 \mathrm{~mm} / \mathrm{min}$ at a magnification of $1,000 \mathrm{x}$

Fracture propagation through the grains is clearly visible in a few marked grains in Fig. 8, which is characterized by a stepped fracture surface, meaning that the fracture jumps from one cleavage plane to another within the same grain.

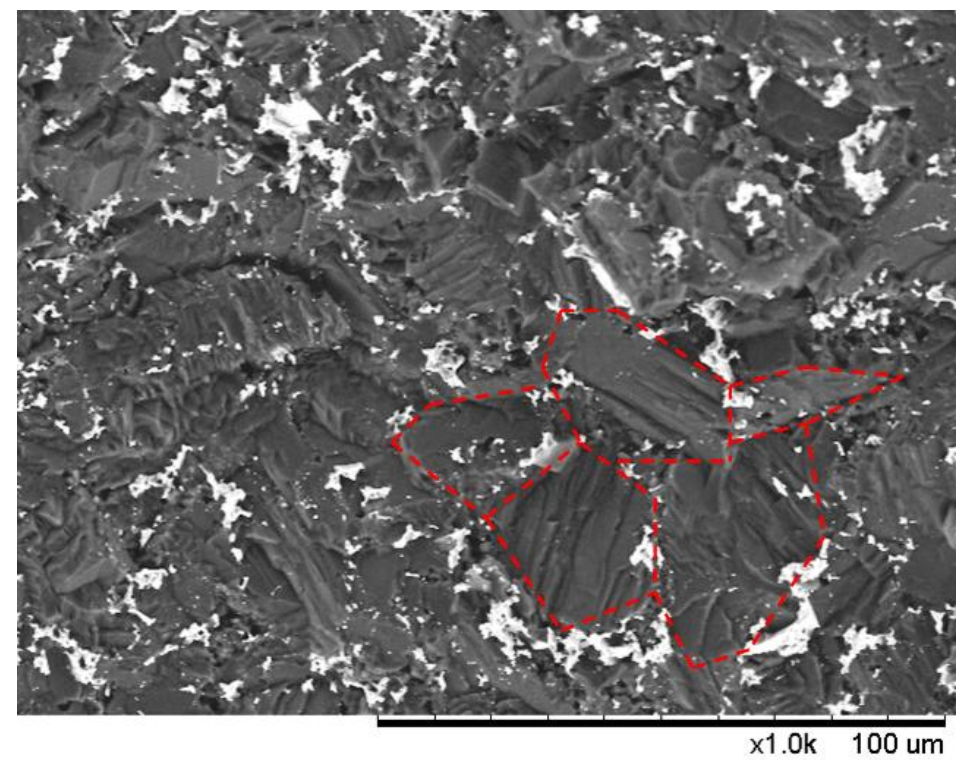

Figure 8. Scanning electron micrograph showing the fracture surface of grade B sample fractured at $0.3 \mathrm{~m} / \mathrm{s}$ at a magnification of $1,000 \mathrm{x}$

A very rough and jagged fracture surface appears at $5 \mathrm{~m} / \mathrm{s}$, as shown in Fig. 9, also evidenced with larger subsurface cracks. 


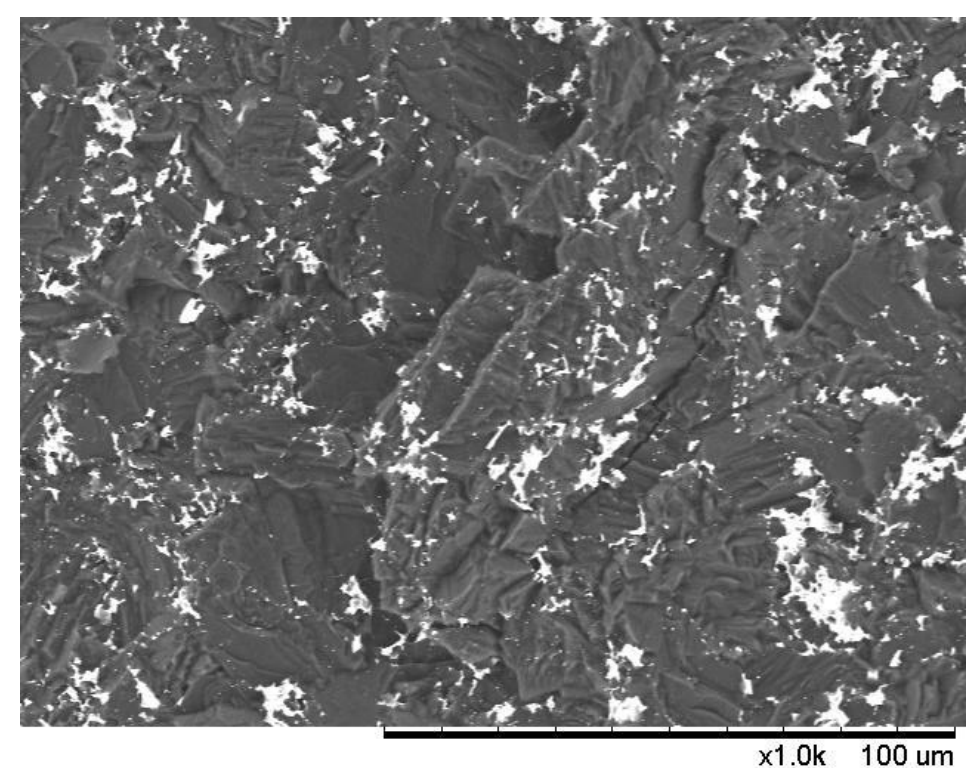

Figure 9. Scanning electron micrograph showing the fracture surface of grade B sample fractured at $5 \mathrm{~m} / \mathrm{s}$ at a magnification of $1,000 \mathrm{x}$

A closer view of the combination of intergranular and transgranular fracture is shown in Fig. 10. This fractograph shows $100,000 \times$ magnified fracture surface of grade B specimen fractured at $5 \mathrm{~m} / \mathrm{s}$, where the grain boundaries are clearly visible, characterizing intergranular fracture. Close to the right of the same image, characteristic stepping can be seen, showing a small amount of transgranular fracture taking place there. Light elements surrounding the grains are cobalt inclusions. There was no remarkable difference in the fracture types observed between the specimens fractured at different temperature levels for both fine grained and coarse grained materials.

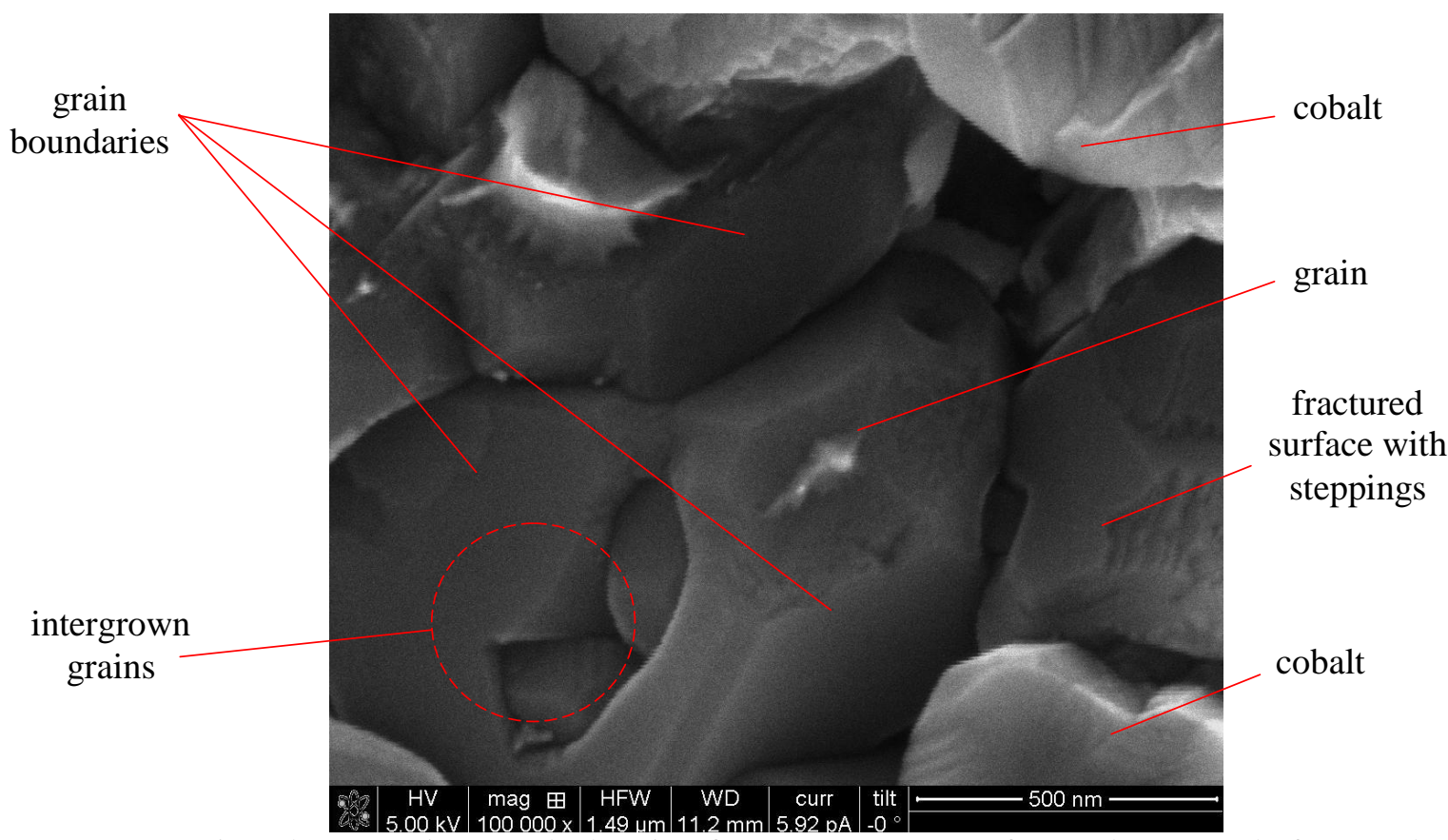

Figure 10. Scanning electron micrograph showing fracture appearance for grade B sample fractured at $5 \mathrm{~m} / \mathrm{s}$ at a magnification of $100,000 \mathrm{x}$

Presented fractographs suggest that adhesion is stronger at lower loading rates resulting in grain boundaries being tougher than the grains themselves. As a consequence, fracture is predominantly of transgranular type, especially within the grade A material. On the other hand, high rates created larger cavities between the grain 
pools (Fig. 5 and Fig. 9) and therefore weaker adhesion, which resulted in predominantly intergranular fracture. The reasons for this material behavior can not be explained based on these micrographs of the fracture surface, and it is necessary to section and polish fractured specimens trying to draw out more significant evidence about the fracture mechanism taking place in polycrystalline advanced ceramics as a function of test conditions.

In order to gain a better perception of the fracture process, fractured samples were sectioned and polished. The sectioning and polishing were performed as shown in Fig. 11.

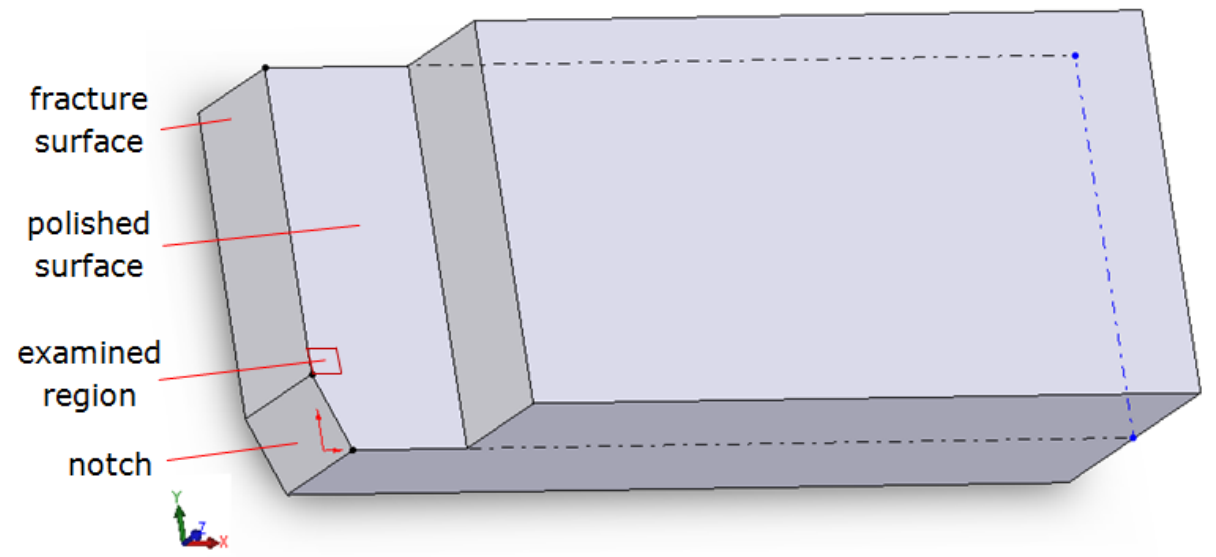

Figure 11. The method of sectioning and polishing the specimens

Edges on the polished surfaces of these specimens were then inspected under FEG-SEM. The location of the examined region was up to $150 \mu \mathrm{m}$ below the notch tip, hence the region of crack initiation. The micrographs obtained for grade A specimens with magnification of 15,000 x are presented in Fig. 12, while Fig. 13 shows micrographs taken for grade $\mathrm{B}$ specimens with 3,000 x magnification, all fractured at room temperature. The crack triggered during experiments propagates in the direction from top to bottom of the images in each case, where the fracture surface is shown on the right of image in Fig. 12 and on the left of image in Fig. 13, as marked in the figures.
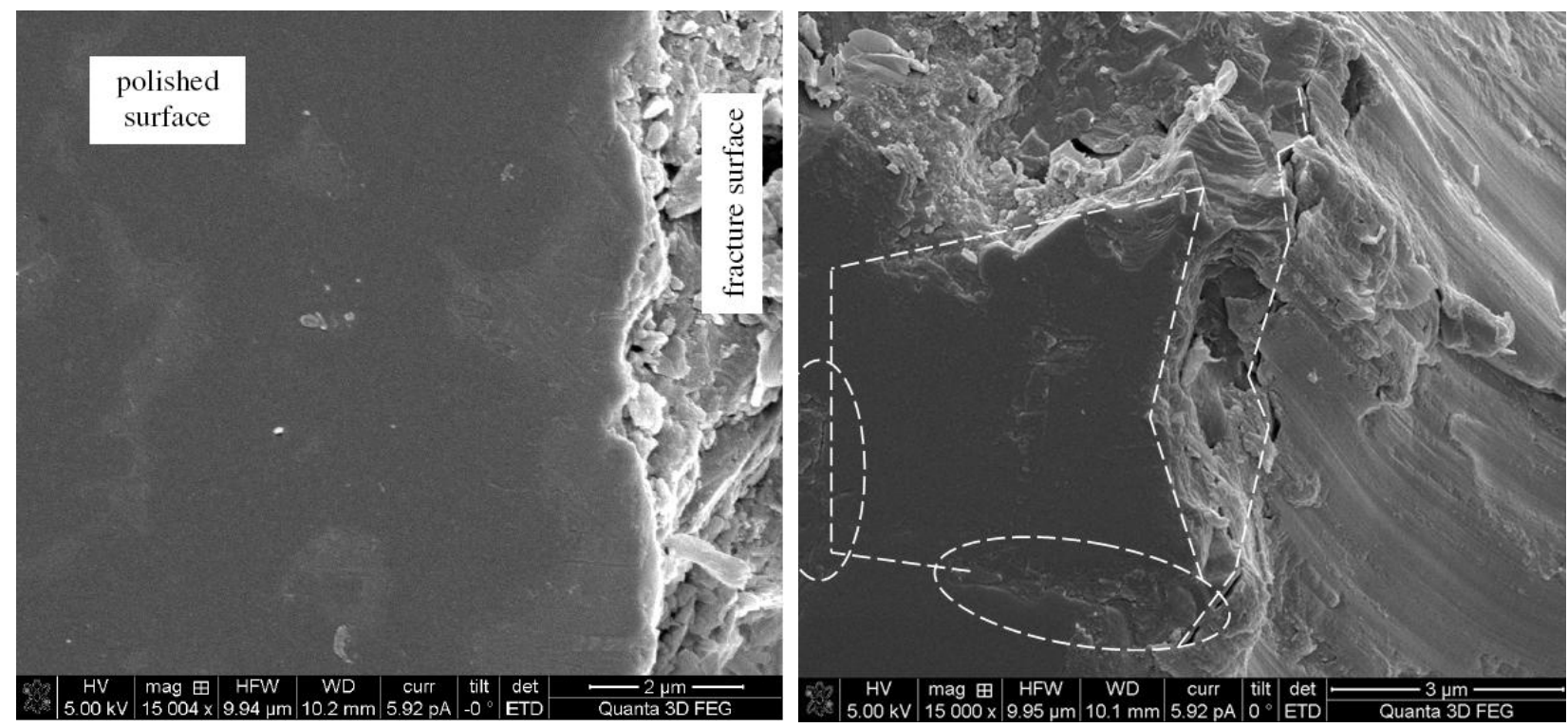

Figure 12. Scanning electron micrograph showing the polished surface of finer grade specimens fractured at

$1 \mathrm{~mm} / \mathrm{min}$ (a) and $5 \mathrm{~m} / \mathrm{s}(\mathrm{b})$ 

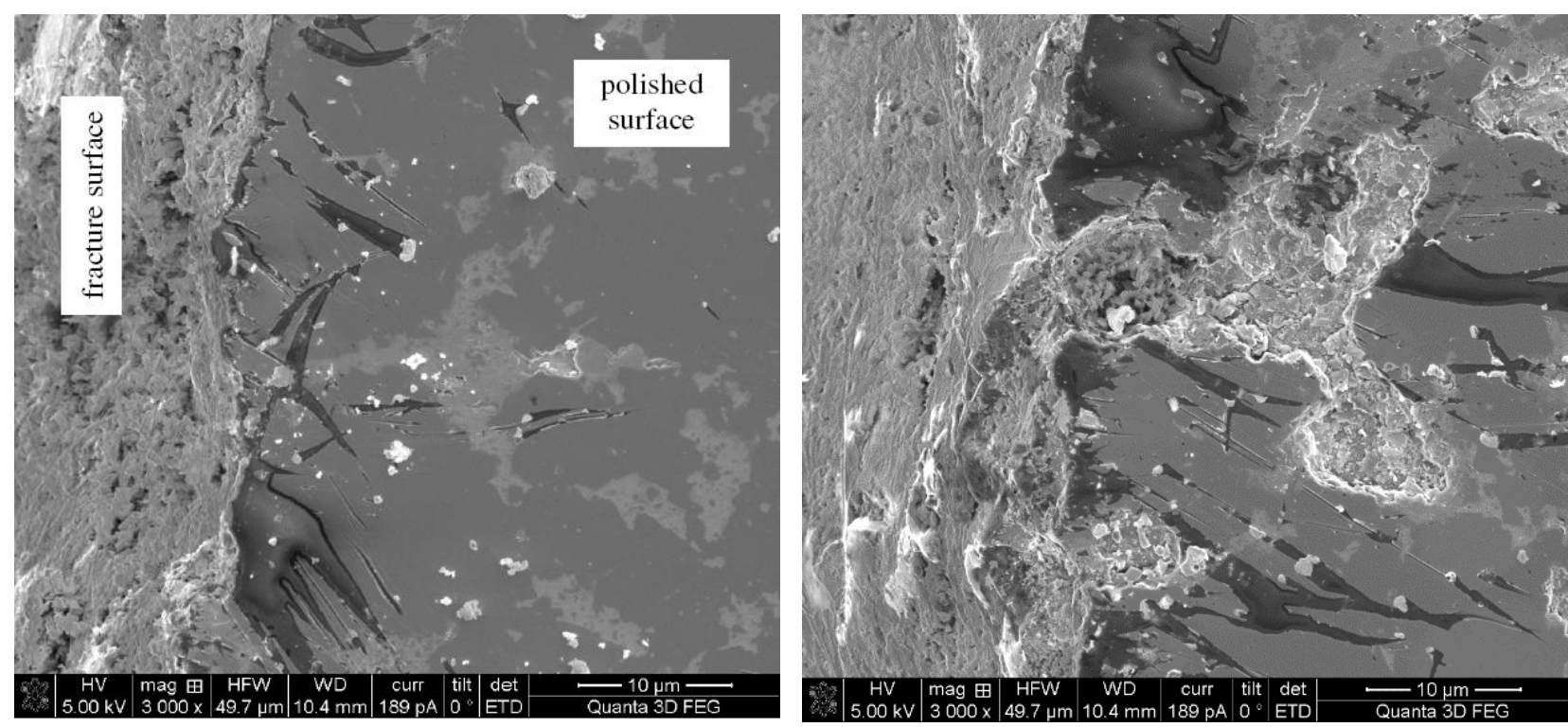

Figure 13. Scanning electron micrograph showing the polished surface of coarser grade specimens fractured at $1 \mathrm{~mm} / \mathrm{min}$ (a) and $5 \mathrm{~m} / \mathrm{s}(\mathrm{b})$

By means of EDX, it was determined that the light grey regions appeared to be the cobalt, whereas dark grey parts pertain to WC grains. Fig. 12 (a) shows the polished surface of the grade A specimen fractured at 1 $\mathrm{mm} / \mathrm{min}$ with a corresponding apparent fracture toughness amounting to $11.1 \mathrm{MPa} \mathrm{m}^{1 / 2}$. It can be seen that the cobalt is completely undamaged, the edge is fairly straight and the fracture toughness is relatively high. Fig. 12 (b) points at the notch root with a clearly visible grain (marked in the image) and deteriorated binder around it (marked by ellipses), corresponding to the specimen fractured at $5 \mathrm{~m} / \mathrm{s}$ with an apparent fracture toughness of $6.0 \mathrm{MPa} \mathrm{m}{ }^{1 / 2}$. Long crack is also visible at the fracture surface, sweeping all the way from the top to the bottom of the image. Comprehensive deterioration of cobalt is noticeable - this region is debonded, providing a path of low fracture resistance and resulting in intergranular fracture.

Fig. 13 (a) shows the polished facet of the specimen fractured at $1 \mathrm{~mm} / \mathrm{min}$ with a corresponding apparent fracture toughness of $12.4 \mathrm{MPa} \mathrm{m}^{1 / 2}$. This time again the binder is completely undamaged. Adhesion between the grains is quite strong, resulting in high fracture toughness and crack propagation occurs through the grains rather than around them, creating a fairly flat fracture surface. Fig. 13 (b) shows characteristic views of the edges of two specimens fractured at $5 \mathrm{~m} / \mathrm{s}$ with the apparent fracture toughness of $7.7 \mathrm{MPa} \mathrm{m}{ }^{1 / 2}$. Identically as for the grade A material, comprehensive deterioration of the cobalt is noticeable and the binder region is debonded, facilitating lower energy crack propagation. The dark lines visible in Fig. 13 are introduced by the sectioning process and are commonly called the gouging effect.

A comparative overview of the sectioned surfaces of one grade A sample fractured at the quasistatic loading rate and other fractured at the dynamic loading rate is given in Fig. 14. Smaller magnification was used in order to get a better view over a greater region. It is noticeable that the binder in areas close to the edge is significantly disintegrated during dynamic fracture (b) extending up to $30 \mu \mathrm{m}$ beneath the fractured surface, as contrasted with the fracture at the quasi-static loading rate (a), where the binder remained completely wellpreserved. 


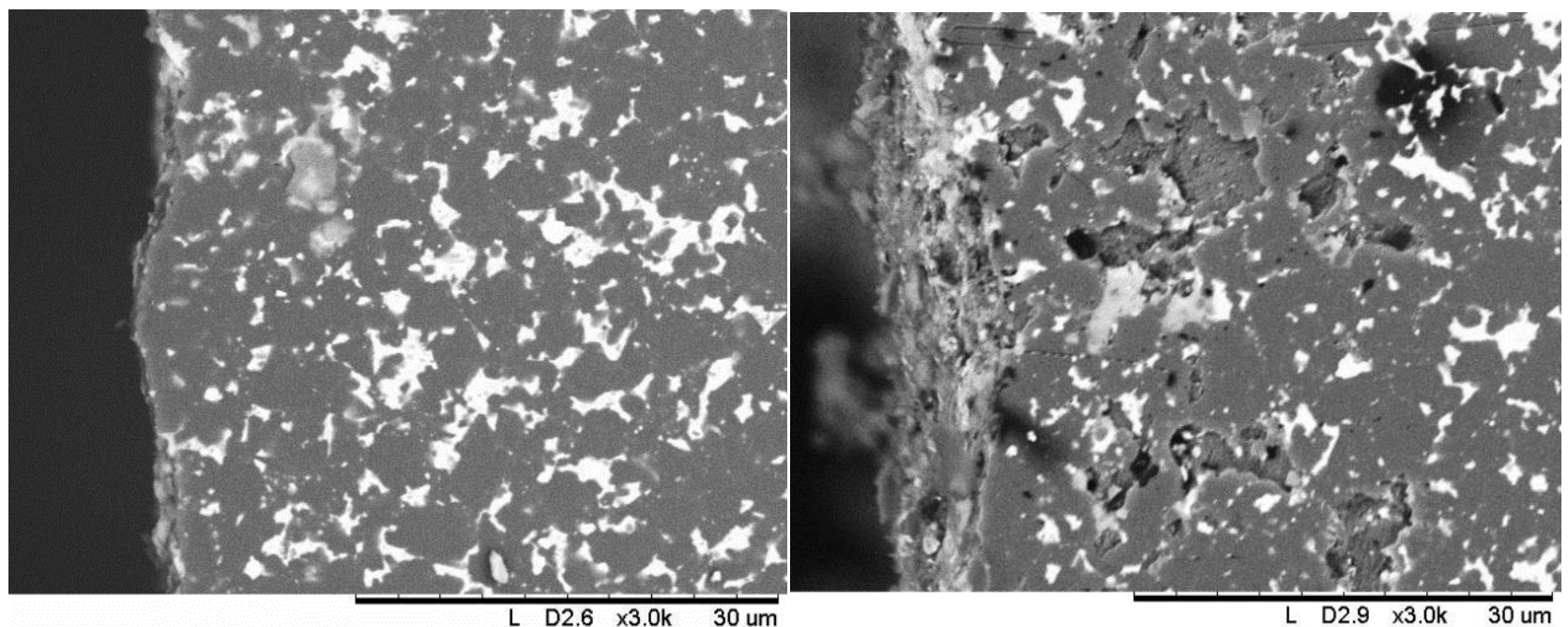

Figure 14. Scanning electron micrographs showing the polished surface of finer grade specimens, fractured at quasistatic (a) and dynamic rate (b), at a magnification of 3,000 x

\section{Conclusions}

Polycrystalline advanced ceramics are finding increased application in industry, where brittle fracture can often render the cutting tool unfit for purpose. In applications such as oil well drilling, the replacement of the cutter head is a time-consuming and costly exercise. The characterization of its fracture properties is therefore of fundamental importance for the classification of existing materials and the development of improved grades in the future. The present paper has presented microscopy studies of the fracture behavior of two grades of polycrystalline advanced ceramics specimens subjected to a span of loading rates between $1 \mathrm{~mm} / \mathrm{min}$ and 5 $\mathrm{m} / \mathrm{s}$, as well as a range of temperatures between room temperature and $600^{\circ} \mathrm{C}$. These two grades contained different mean WC grain sizes of 6 and $30 \mu \mathrm{m}$ and, therefore, different amounts of cobalt utilized as a binder in the mixture. As the finer grade composite contains more grain boundaries, a higher percentage of cobalt binder may be anticipated, located within smaller cobalt pools. On the other hand, coarser grade has greater cobalt pools due to larger grains. This can clearly be seen comparing micrographs for fine and coarse grade material.

The paper explains fracture mechanisms of polycrystalline advanced ceramics based on microscopy analysis observations of the fractured specimens. This also complies with outcomes of other previously published work within the same research. Experimental results of plane strain fracture toughness obtained earlier on singleedge-V-notched-beam specimens were supported with microscopy analysis. These findings establish a clear connection between the fracture toughness results and the fracture mechanisms visible on and beneath the fracture surfaces, revealing adiabatic conditions that occur at the crack tip during fracture. This behavior has not been observed earlier in literature for the same type of material.

At quasistatic rates the fracture toughness was found to be relatively constant. There is enough time for the heat generated at the crack tip to be conducted into the bulk material, so the process is essentially isothermal. At dynamic rates the fracture toughness drops consistently, most likely due to a temperature increase at the crack tip. Because of the tremendously short time scales available for fracture to initiate and propagate, heat originated in very small field ahead of the crack tip remains captured and adiabatic environment takes place, which is suggested by the fact that material satisfies an adiabatic thermal decohesion model as found in [3]. This results in the temperature and temperature gradients in observed field becoming elevated, leading to the deterioration and damage of the cobalt phase due to differences in the coefficients of thermal expansion of ceramics grains and cobalt binder, and a corresponding decrease in fracture toughness. Therefore, it may be concluded that cobalt plays a major role during the fracture of polycrystalline advanced ceramics and it is mainly responsible for the deterioration of its fracture properties under the extreme working conditions encountered during the actual cutting process.

Apart from the theory of adiabatic heating in the vicinity of the crack tip resulting in lower $K_{I c}$ values at high loading rates, it is also known that cobalt, like most metals with a face centered cubic microstructure, is very rate sensitive with the flow stress seen to be an increasing function of strain rate [11,12]. Therefore, the faster it is loaded, the more brittlely it behaves, and the rate dependency in the material is mainly due to the 
influence of the cobalt binder phase. Considering all these findings, it may be concluded that the cobalt binder phase is responsible for the deterioration in fracture toughness of polycrystalline advanced ceramics sintered compacts at high loading rates.

\section{References}

[1] R. Morrell, "Fracture toughness testing for advanced technical ceramics: Internationally agreed good practice", Advances in Applied Ceramics, vol. 105, no. 5, pp. 88-98, 2006.

[2] Y. Guo, T. Staedler, J. Müller, S. Heuser, B. Butz and X. Jiang. "A detailed analysis of the determination of fracture toughness by nanoindentation induced radial cracks", Journal of the European Ceramic Society, (in press).

[3] M. Petrovic and E. Kljuno, "Thermal decohesion model validity for polycrystalline advanced ceramics", International Journal of Advanced and Applied Sciences, vol. 4, no. 7, pp. 1-4, 2017.

[4] M. Petrovic, D. Carolan, A. Ivankovic and N. Murphy, "Role of rate and temperature on fracture and mechanical properties of PCD”, Key Engineering Materials, vol. 452, pp. 153-156, 2011.

[5] L. Fletcher and F. Pierron, "An image-based inertial impact (IBII) test for tungsten carbide cermets", Journal of Dynamic Behavior of Materials, vol. 4, no. 4, pp. 481-504, 2018.

[6] L. Fletcher, J. Van Blitterswyk and F. Pierron, "A novel image-based inertial impact (IBII) test for the transverse properties of composites at high strain rates", Journal of Dynamic Behavior of Materials, vol. 5, no. 1, pp. 65-92, 2019.

[7] G. Hütter, L. Zybell, Recent Trends in Fracture and Damage Mechanics, Springer International Publishing, 2016.

[8] M. Petrovic, A. Ivankovic and N. Murphy, "The mechanical properties of polycrystalline diamond as a function of strain rate and temperature", Journal of European Ceramic Society, vol. 32, pp. 3021-3027, 2011.

[9] M. Nazari, B.L. Hancock, J. Anderson, K.D. Hobart, T.I. Feygelson, M.J. Tadjer, B.B. Pate, T.J. Anderson, E.L. Piner and M.W. Holtz, "Optical characterization and thermal properties of CVD diamond films for integration with power electronics", Solid-State Electronics, vol. 136, no. 1, pp. 12-17, 2017.

[10] B. Dai, J. Zhao, V. Ralchenko, A. Khomich, A. Popovich, K. Liu, G. Shu, G. Gao, S. Mingqi, L. Yang, P. Lei, J. Han and J. Zhu, "Thermal conductivity of free-standing CVD diamond films by growing on both nuclear and growth sides", Diamond and Related Materials, vol. 76, no. 1, pp. 9-13, 2017.

[11] S. Dreuilhe, F. Davis, C.R. Siviour and F. Pierron, "Image-based inertial impact tests on an aluminum alloy", Advancement of Optical Methods in Experimental Mechanics, vol. 3, no. 2, pp. 219-223, 2017.

[12] F. Pierron and L. Fletcher, "Generalized Stress-Strain Curves for IBII Tests on Isotropic and Orthotropic Materials", Journal of Dynamic Behavior of Materials, vol. 5, no. 2, pp. 180-193, 2019. 